\title{
Widespread kidney anomalies in children with Down syndrome
}

\author{
Lavinia Postolache ${ }^{1} \cdot$ Afshin Parsa $^{2} \cdot$ Paolo Simoni $^{3} \cdot$ Grammatina Boitsios $^{3} \cdot$ Khalid Ismaili $^{4} \cdot$ Thierry Schurmans $^{4}$. \\ Anne Monier ${ }^{4} \cdot$ Georges Casimir $^{4} \cdot$ Adelin Albert $^{5} \cdot$ Cameron F. Parsa $^{6,7}$
}

Received: 13 June 2021 / Revised: 25 December 2021 / Accepted: 27 December 2021

(c) The Author(s), under exclusive licence to International Pediatric Nephrology Association 2022

\begin{abstract}
Background Rare autopsy studies have described smaller kidneys as well as urinary tract anomalies in Down syndrome. This observation has never been investigated in vivo and little is known about the possible consequences upon kidney function. Here we wish to confirm whether children with Down syndrome have smaller kidneys and to evaluate their kidney function in vivo.

Methods This retrospective cohort study enrolled 49 children with Down syndrome, as well as 49 age- and sex-matched controls at the Queen Fabiola Children's University Hospital in Brussels, Belgium. Doppler and kidney ultrasonography, spot urine albumin to creatinine ratio, estimated glomerular filtration rate (eGFR), and anthropometric data were recorded. Results Kidney size in children with Down syndrome was smaller than age- and sex-matched controls in terms of length $(p<0.001)$ and volume $(p<0.001)$. Kidney function based on eGFR was also decreased in Down syndrome compared to historical normal. Twenty-one of the children with Down syndrome (42\%) had eGFR $<90 \mathrm{~mL} / \mathrm{min} / 1.73 \mathrm{~m}^{2}$, with 5 of these $(10 \%)$ having an eGFR $<75 \mathrm{~mL} / \mathrm{min} / 1.73 \mathrm{~m}^{2}$. In addition, 7 of the children with Down syndrome (14\%) had anomalies of the kidney and/or urinary tract that had previously been undiagnosed.

Conclusions Children with Down syndrome have significantly smaller kidneys than age-matched controls as well as evidence of decreased kidney function. These findings, in addition to well-noted increased kidney and urologic anomalies, highlight the need for universal anatomical and functional assessment of all individuals with Down syndrome.
\end{abstract}

Keywords Down syndrome $\cdot$ Trisomy $21 \cdot$ Kidney anomalies $\cdot$ Kidney size $\cdot$ CAKUT

Cameron F. Parsa

cfparsa@gmail.com

1 Department of Ophthalmology, Queen Fabiola Children's University Hospital, Université Libre de Bruxelles, Brussels, Belgium

2 The Division of Kidney, Urologic, and Hematologic Diseases, National Institute of Diabetes and Digestive and Kidney Diseases, Bethesda, MD, USA

3 Department of Radiology, Queen Fabiola Children's University Hospital, Université Libre de Bruxelles, Brussels, Belgium

4 Department of Pediatrics, Queen Fabiola Children's University Hospital, Université Libre de Bruxelles, Brussels, Belgium

5 Department of Biostatistics, Liège University Hospital, Liège, Belgium

6 Department of Ophthalmology, Erasmus Hospital, Université Libre de Bruxelles, 808 Route de Lennik, B-1070 Brussels, Belgium

7 Faculty of Medicine, Sorbonne University, Paris, France

\section{Abbreviations}

eGFR Estimated glomerular filtration rate

CKD Chronic kidney disease

BSA Body surface area

IDMS Isotope-dilution mass spectrometry

PACS Picture archiving and communication system

SD Standard deviation

\section{Introduction}

Kidney and urinary tract anomalies have been considered to constitute the fourth most common major congenital birth defect in Down syndrome, preceded by heart defects and gastrointestinal and musculoskeletal anomalies, with prevalences at birth varying between 0.03 and 3.2\% [1-3]. An increased frequency of kidney and urinary tract pathology developing later in life has also been reported in individuals with Down syndrome [4-7]. Little is known about the cause of these congenital anomalies and their long-term 
effects on kidney function. Though not the most severely handicapping, the vast majority of children with Down syndrome have various ocular anomalies [8-10] with an even higher prevalence of congenital ocular anomalies relatable to hypoplasia [10-13]. With shared features of development, there are a number of known associations between ocular and kidney anomalies. These appear most specifically in the von Hippel-Lindau and papillorenal syndromes, both related to abnormalities of angiogenesis [14-16]. We hypothesized that the degree of kidney involvement in Down syndrome might have been yet underestimated and that, similar to the papillorenal syndrome, in addition to congenital anomalies of the kidney and urinary tract, smaller kidney size and reduced function might also be highly prevalent.

Two prior autopsy studies in individuals with Down syndrome had reported reductions in kidney mass, one revealing a $14.4 \%$ decrease [17], and the other $31.1 \%$ [18]. However, in vivo kidney size in children with Down syndrome has not yet been systematically assessed. Using kidney ultrasonography, we wished to determine whether smaller kidneys are a developmental feature of children with Down syndrome as compared to healthy controls. Urinary tract anomalies, eGFR, and albuminuria were also evaluated.

\section{Methods}

\section{Type of study}

This is a single-center, retrospective cohort study comparing the association of children with Down syndrome (Trisomy 21) as an exposure to those without Down syndrome, with kidney size and function.

\section{Subjects and setting}

Forty-nine children with Down syndrome, aged between 0 and 18 years, and forty-nine age- and sex-matched healthy volunteers between October 2017 and May 2019, were prospectively included in the study to compare kidney parameters.

The subjects included were children with Down syndrome followed by a multidisciplinary team at the Queen Fabiola Children's University Hospital. All parents were invited to take part; we included in consecutive order those children for whom the parents consented to participate. We included healthy volunteers recruited via announcement as controls. Age- and sex-matched controls were excluded if they had already known kidney and urinary tract anomalies. Any subject who could not cooperate sufficiently for the study-related examinations was also excluded.

All clinical investigations were performed at Queen Fabiola Children's University Hospital in partnership with the
Université Libre de Bruxelles in Brussels, Belgium. Serum creatinine and urine albumin and creatinine measures were performed at the University Central Laboratory (LHUBULB), Brussels, Belgium.

Written informed consent was obtained for all subjects with both parents providing consent. Approval for this study was obtained from the Institutional Review Boards and Institutional Ethics Committees of both the Queen Fabiola Children's University Hospital (CEH 69/17), and the Erasmus Hospital (P2017/391; B4062017329655). All examinations were performed in accordance with the principles and tenets of the Declaration of Helsinki.

\section{Examinations}

\section{Physical examination}

Weight, height, and blood pressure data were recorded for all children. Blood pressure was measured using an appropriately sized sphygmomanometer in the sitting position with the subject's arm supported at the level of the heart and recorded to the nearest millimeter of mercury. Systolic and diastolic blood pressures were measured 3 times, at 2-to3 -min intervals. The arithmetic mean of the last 2 blood pressure measurements was then used as the mean blood pressure. Body surface area (BSA) was calculated using the Mosteller formula [19] where BSA = the square root of (weight $(\mathrm{kg}) \times$ height $(\mathrm{m}) / 3600)$.

\section{Laboratory analysis}

Kidney function was assessed using the estimated glomerular filtration rate (eGFR) using the Bedside Schwartz formula [20] which estimates the glomerular filtration rate in children and adolescents, and incorporates serum creatinine along with height and sex. Creatinine levels were determined according to the spectrophotometric Jaffe method [21] using a Roche Cobas platform, based on the chemical reaction between creatinine and picric acid in alkaline conditions [22] with calibration traceable to IDMS reference measurement procedure.

We determined the level of albuminuria from a spot urine sample collected from the first morning void, and we calculated the urine albumin to creatinine ratio. Urinalysis was performed in all children with Down syndrome, as well as their age- and sex-matched controls.

\section{Kidney and urinary tract Doppler ultrasound}

Kidney Doppler ultrasound and two-dimensional kidney and urinary tract ultrasonography were performed for all children. Scans were acquired with the child in prone position. 
We used an EPIQ 7 Model ultrasound device (Philips, Amsterdam, the Netherlands) equipped with an $8-\mathrm{MHz}$ transabdominal curved probe. Measurements for each kidney included maximum kidney bipolar length in the sagittal plane along with kidney width and cortical thickness in an axial plane perpendicular to each other at the level of the renal hilum. A visual estimation of the intensity of corticomedullary differentiation was performed by the same radiologist (GB). Doppler ultrasonography was used to determine renal arterial resistivity indices, including the renal arteries and peripheral (arciform) arteries at the 3 poles of each kidney. The arithmetic mean of the Doppler estimates at the 3 poles was used in the statistical analysis.

All kidney measurements were reviewed by a second radiologist (PS) who was blinded to the subjects' demographics and clinical and laboratory findings, 3 months later using the picture archiving and communication system (PACS) in order to check the consistency of the data. Kidney volume was subsequently calculated in cubic centimeters using the equation for an ellipsoid: volume $\left(\mathrm{cm}^{3}\right)=$ mean length $(\mathrm{L}) \times$ mean width $(\mathrm{W}) \times$ mean depth $(\mathrm{D}) \times 0.523$.

\section{Accounting for effect of body size on kidney size}

Kidney length has been shown to be associated in varying degree with age, sex, height, and weight, which are all correlated to each other. BSA, which accounts for height and weight, has been noted as a strong correlate for kidney size and is also used as the standard for normalizing GFR values to body size. Accordingly, we considered BSA to be an appropriate measure to normalize differences in body size between Down syndrome and controls. Moreover, as a secondary approach, we applied a previously developed equation which can be used to calculate expected kidney bipolar length in children, based on age, weight, and height [23] to compare with actual bipolar kidney length in our study participants. The formulas used were right kidney length $=5.91+$ age $(0.04)+$ height $(0.01)+$ weight $(0.03)$ and left kidney length $=5.58+$ age $(0.05)+$ height $(0.01)+$ weight $(0.021)$ [23].

\section{Statistical analysis}

Results were expressed as mean and standard deviation (SD) for quantitative variables and as frequency tables (numbers and percent) for categorical variables. The correlation coefficient was used to quantify the association between 2 variables. Matched groups were compared by the unpaired $t$-test or the Wilcoxon signed-rank test for skewed data. The paired $t$-test was also used to compare actual versus expected kidney length in cases and controls, separately. The McNemar test and the test of symmetry were applied to compare paired proportions. All tests were two-sided and the significance level was set at $5 \%(p<0.05)$. All calculations were performed with SPSS (IBM SPPS, version 2020, Armonk, NY) or SAS software version 9.4 (SAS Institute Inc., Cary, NC).

\section{Results}

\section{Demographics}

Kidney function and morphology were evaluated in 49 children with Down syndrome and in their age- and sex-matched controls; thus, 49 pairs of subjects/controls were available for the statistical analysis. The mean age of subjects and controls was $8.0 \pm 4.2$ years and $8.3 \pm 4.0$ years, respectively, and there were 30 boys and 19 girls in each group. The 2 groups showed slight but not significant difference in race, with $18 \%$ African ancestry in Down syndrome versus $12 \%$ in controls $(p=0.41)$.

\section{Clinical measures}

Anthropometric data of the 49 pairs of subjects and controls summarized in Table 1 show that children with Down syndrome were shorter and had a higher BMI than their corresponding controls. In the present study, the mean systolic and diastolic blood pressures were the same in children with Down syndrome compared to controls (Table 1).

\section{Laboratory test results}

Mean urine albumin to creatinine ratios were comparable at $9.3 \mathrm{mg} / \mathrm{g}$ and $9.5 \mathrm{mg} / \mathrm{g}$ in Down syndrome and in controls, respectively. Similarly, the number of individuals with microalbuminuria, defined as $20-50 \mathrm{mg} / \mathrm{L}$, was 7 among Down syndrome children versus 6 in controls.

Table 1 Anthropometric data for children with Down syndrome as compared to age- and sex-matched healthy volunteers (controls)*

\begin{tabular}{llll}
\hline Variable & $\begin{array}{l}\text { Children with Down } \\
\text { syndrome } \\
\mathrm{N}=49\end{array}$ & $\begin{array}{l}\text { Controls } \\
\mathrm{N}=49\end{array}$ & p-value \\
\hline Age & $8.0 \pm 4.2$ & $8.3 \pm 4.0$ & 0.72 \\
Weight $(\mathrm{kg})$ & $29.4 \pm 18.5$ & $30.4 \pm 16.1$ & 0.77 \\
Height $(\mathrm{cm})$ & $115 \pm 20$ & $128 \pm 24$ & $<0.003$ \\
BMI & $20.2 \pm 6.3$ & $17.3 \pm 3.1$ & 0.005 \\
BSA & $0.95 \pm 0.36$ & $1.03 \pm 0.36$ & 0.27 \\
SBP $(\mathrm{mmHg})$ & $108 \pm 12$ & $109 \pm 12$ & 0.53 \\
DBP $(\mathrm{mmHg})$ & $61.0 \pm 8.4$ & $61.3 \pm 7.7$ & 0.99 \\
\hline
\end{tabular}

Key: Controls (age- and sex-matched healthy volunteers)

$B M I$, body mass index; $B S A$, body surface area; $S B P$, systolic blood pressure; $D B P$, diastolic blood pressure; $N$, number

* Results are expressed as mean \pm standard deviation (SD) 
Serum levels of creatinine and the eGFR Schwartz formula were evaluated in children with Down syndrome only, as shown in Table 2. The average eGFR was $94.3 \mathrm{~mL} /$ $\mathrm{min} / 1.73 \mathrm{~m}^{2}$, which is lower than expected based on historical controls. We found 21 of the children to have an eGFR $<90 \mathrm{~mL} / \mathrm{min} / 1.73 \mathrm{~m}^{2}$ (only 1 with age $<2$ years) and 5 of them with eGFR $<75 \mathrm{~mL} / \mathrm{min} / 1.73 \mathrm{~m}^{2}$. Given potential limitations in Jaffe-based creatinine measures in younger children, we also performed a sensitivity analysis in our adolescent subpopulation of 8 children aged 12 to 17 and found their eGFR to be even lower at $85.4 \mathrm{~mL} / \mathrm{min} / 1.73 \mathrm{~m}^{2}$, of which $75 \%$ had an eGFR $<90 \mathrm{~mL} / \mathrm{min} / 1.73 \mathrm{~m}^{2}$.

\section{Imaging findings}

Unadjusted data relating to kidney morphology as estimated by bidimensional ultrasonography are displayed in Table 2 for children with Down syndrome and controls. We noted significant differences for kidney bipolar length $(7.56 \pm 1.2$ vs. $8.27 \pm 1.13 \mathrm{~cm} ; p<0.0001)$ and volume $(52.2 \pm 25.1$ vs. $\left.69.8 \pm 29.2 \mathrm{~cm}^{3} ; p<0.001\right)$ as well as other kidney measures (Table 2). Considering differences in body size in the 2 groups, we also adjusted for BSA alone or along with race and age and found differences in kidney length and volume in Down syndrome versus controls to both still be highly statistically significant with consistent $p$-values $<0.001$ in all of our models.

The kidney bipolar length observed in controls was consistent with the estimated kidney length when using an equation developed to estimate expected kidney size based on age, height, and weight [23] with actual versus estimated lengths being $8.27 \pm 1.13 \mathrm{~cm}$ and $8.18 \pm 0.81 \mathrm{~cm}$ $(p=0.28)$, respectively. However, in children with Down syndrome, the measured mean kidney length was less than the calculated expected kidney size study at $7.56 \pm 1.25 \mathrm{~cm}$ versus $8.01 \pm 0.83 \mathrm{~cm}(p<0.001)$, respectively.

The resistivity index of the central renal artery was evaluated by kidney Doppler ultrasound in 33 pairs of subjects and controls; no significant differences were found between the two groups $(0.713 \pm 0.074$ vs. $0.704 \pm 0.082 ; p=0.56)$. Similar homogeneity was observed with regard to mean resistivity index in the arciform arteries, which was evaluated for 35 pairs of subjects and controls $(0.673 \pm 0.065$ vs. $0.668 \pm 0.060 ; p=0.74)$. For all these measurements, the results were comparable if we considered each kidney individually; this was the case regardless of whether we used bidimensional ultrasonography or Doppler ultrasonography.

Data analysis allowed us to identify 5 additional children with Down syndrome with previously unsuspected kidney and urinary tract anomalies. One had bilateral hydronephrosis and another had unilateral hydronephrosis; both of these children had pyelocaliceal dilatation. We also detected 1 child with pyelectasis, and 2 children with reduced corticomedullary differentiation requiring further investigation. No kidney or urinary tract anomalies were detected in the control group.

Given that 27 of the Down syndrome participants had a history of congenital heart disease, we checked to see if it might correlate with kidney function and found no association between congenital heart disease and eGFR, albuminuria, or kidney length.

\section{Discussion}

The present prospective study is the first investigation to systematically compare the ultrasonography features of kidneys in children with Down syndrome to a control
Table 2 Kidney morphology and function for children with Down syndrome as compared to age- and sex-matched healthy volunteers (controls)*

\begin{tabular}{llll}
\hline Variable** & $\begin{array}{l}\text { Children with } \\
\text { Down syndrome } \\
\mathrm{N}=49\end{array}$ & $\begin{array}{l}\text { Controls } \\
\mathrm{N}=49\end{array}$ & p-value \\
\hline Kidney max bipolar length $(\mathrm{cm})$ & $7.57 \pm 1.25$ & $8.27 \pm 1.13$ & $<0.001$ \\
Cortical thickness $(\mathrm{cm})$ & $0.84 \pm 0.3$ & $0.80 \pm 0.35$ & 0.52 \\
Kidney width at the hilum level $(\mathrm{cm})$ & $3.38 \pm 0.68$ & $3.69 \pm 0.61$ & 0.022 \\
Kidney thickness at the hilum level $(\mathrm{cm})$ & $3.60 \pm 0.66$ & $4.20 \pm 0.78$ & $<0.001$ \\
Kidney volume $\left(\mathrm{cm}^{3}\right)$ & $52.2 \pm 25.1$ & $69.8 \pm 29.2$ & $<0.001$ \\
Abnormal cortico-medullary differentiation (number, $\%)$ & $3(6.1)$ & $0(0.0)$ & 0.39 \\
Urine albumin to creatinine ratio $(\mathrm{mg} / \mathrm{g}$; number) & $9.30 \pm 12.2$ & $9.50 \pm 9.2$ & 0.94 \\
Serum creatinine (mg/dL; number) & $0.5 \pm 0.1$ & $\mathrm{NA}$ & $\mathrm{NA}$ \\
eGFR Schwartz formula mL/min/1.73 m ${ }^{2}$ & $94.3 \pm 16.6$ & $\mathrm{NA}$ & $\mathrm{NA}$ \\
\hline
\end{tabular}

Key: Controls (age- and sex-matched healthy volunteers)

$G F R$, glomerular filtration rate; $N$, number

*Results are expressed as mean \pm standard deviation (SD), or number (\%)

${ }^{* *}$ Evaluation by two-dimensional ultrasound of the kidneys, and ultrasound of the urinary tract 
population. Two prior reports based on autopsy results suggested that individuals with Down syndrome had smaller kidneys compared to unaffected individuals $[17,18]$. In the present study, ultrasound-based measures in vivo confirm that children with Down syndrome have significantly smaller kidneys developmentally, based on either length or volume, while accounting for body surface area, than matched controls. We also verified that the kidney lengths in our control population matched the expected kidney length, based on an algorithm derived using age, height, and weight in an independent population, whereas the kidneys of children with Down syndrome were significantly smaller than the calculated expected lengths.

We also observed previously unsuspected kidney and urinary tract anomalies in 7 out of the 49 (14\%) children with Down syndrome. This result was in keeping with previous studies, evaluating children and adolescents with Down syndrome showing a prevalence of kidney and urinary tract anomalies between 7.2 and 20\% [4-6]. Previous population-based registry studies reported that the majority of morbidity-related kidney and urinary tract congenital defects were due to an obstructive syndrome [2, 24], including vesicoureteral reflux [25], obstructive uropathies (focal cystic dysplasia, hydronephrosis, bladder neck stenosis, and hydroureters) [17], and posterior urethral valves [3]. Severe non-neurogenic bladder sphincter dysfunctions have also previously been found in up to $30 \%$ of children, and in $8.7 \%$ of adults, with Down syndrome [26, 27].

In this study, we also noted, as our secondary endpoint, overt decrease in kidney function in children and adolescents with Down syndrome as compared to historical controls. Most notably, we found $42 \%$ of our Down syndrome patients to have eGFR $<90 \mathrm{~mL} / \mathrm{min} / 1.73 \mathrm{~m}^{2}$. Even more strikingly, $10 \%$ of these had an eGFR $<75 \mathrm{~mL} / \mathrm{min} / 1.73 \mathrm{~m}^{2}$ meeting suggested criteria for significant CKD [28]. Similarly, Yamakawa and colleagues noted that eGFR and cystatin-C eGFR in Down syndrome were approximately $80 \%$ that of healthy children [29]. A reduced glomerular filtration and tubular secretion (the reduced clearance of creatinine and uric acid) was also reported in older individuals with Down syndrome during their third and fourth decades of life [30, 31].

We had expected to find and confirm a mild kidney hypoplasia as a developmental anomaly in Down syndrome, given the proportionally higher documented levels of endostatin, an inhibitor of angiogenesis encoded on chromosome 21 along with several other angiogenesis inhibitor genes such as DSCR1, triply expressed [32-34]. Hence, we expected the susceptibility of certain organs, notably the kidneys and eyes, heavily dependent on angiogenesis for their development $[14,16]$ to be affected. Such kidney as well as ocular hypoplasia attributed to reduced angiogenesis had been noted in papillorenal syndrome $[14,16]$. Growth and guidance factors involved in angiogenesis have been found also to be responsible for the growth of other tubular structures in the body, including axons as well as those formed by the kidney epithelial cells from the ureteric bud [35-38]. Therefore, deficiency in systemic angiogenesis can disturb ureteric branching, morphogenesis, and elongation, and perturb the microvessel density of the distal ureter and the angle of insertion of the ureter into the bladder resulting in vesicoureteral reflux (VUR), as well as produce kidney hypoplasia [16, 37, 38].

Indeed, on histological section of kidneys from 25 fetuses with Down syndrome, Desogus and associates found more immature and morphologically abnormal glomeruli that resulted in an overall increase in glomerular area; collectively, these abnormalities suggested impaired nephrogenesis and glomerular development, which could result in continual loss of kidney function and hypertension later in life [39]. Lo and co-workers reported various abnormalities including immature glomeruli and focal segmental glomerulosclerosis, with glomerular microcysts representing a significantly different feature in a series of 43 Down syndrome autopsies with controls [40].

Currently, there are no official guidelines to screen for kidney defects in patients with Down syndrome [41, 42]. Evidence from some recent reports indicate a potential benefit in performing such screening procedures in newborns [4] as well as in subjects entering their second and third decades of life [43]. The findings of our study support such notions as kidney and urinary tract anomalies could be missed if imaging examination is not systematically performed. Screening for kidney function in individuals with Down syndrome would allow proper assessment for strict blood pressure control as well as the potential use of reninangiotensin system (RAS) blockade. In addition, follow-up in children with abnormal imaging findings and/or obstruction could be provided in order to better preserve their kidney function going into adulthood [44-46].

\section{Limitations}

The study had some limitations. Examinations that required the subject to remain still were difficult to perform and, in some cases, unfeasible due to difficulties obtaining necessary cooperation (e.g., when measuring the renal resistivity index).

Other limitations were in obtaining several measurements such as serum creatinine in our age- and sexmatched controls since phlebotomy in minors, without a compelling medical reason to do so, was deemed excessively invasive by the Institutional Review Board. However, multiple publications consistently demonstrate higher eGFR in populations of healthy children [47-50]. Calculation of kidney volume based on ultrasound measures are not always accurate, however, and we expect any errors to 
be present in both Down syndrome and controls equally, as the technique and ultrasound operator were the same for both. As such, the difference in volume between the 2 groups is expected to be reasonably accurate. The formula we used for the calculations of expected kidney length was derived in a general population and has not been validated in children with Down syndrome. However, given that it was based on age, height, and weight combined, we felt it might be the most comprehensive estimation tool available. Blood pressure was found to be similar in Down syndrome compared to controls. But, given the shorter stature of individuals with Down syndrome, it is possible that we underestimated their blood pressure in contrast to the controls. However, trunk size is the main determinant of blood pressure association with height, as opposed to leg length [51,52], and since trunk size is fairly similar in Down syndrome compared to healthy controls (i.e., shorter leg length is primary cause of shorter stature in Down syndrome), underestimation of blood pressure in our cases is likely minimal $[53,54]$. We used the Schwartz formula to estimate GFR in our participants with Down syndrome, which may decrease the accuracy of the eGFR in Down syndrome, as creatinine production may be altered [55]. However, lean muscle mass appears to be lower in Down syndrome [56], meaning that this might potentially bias the eGFR to a higher number than actual, and meaning that the actual GFR in our patients may be even lower than the estimated value. Lastly, our lab utilized a Jaffe creatinine assay, calibrated to IDMS, as opposed to an enzymatic assay, as used in the bedside Schwartz eGFR formula, which could lead to increased error. However, we used the Roche Cobas Jaffe platform which, unlike some other platforms, has shown excellent correlation with enzymatic approaches $\left(r^{2}=0.99\right)$, along with negligible bias [57].

\section{Conclusion}

Using ultrasound measurements obtained in vivo, we found that kidneys of children with Down syndrome are significantly smaller than their age- and sex-matched controls. We also noted kidney function to be lower than those of historical controls and confirmed that a significant percentage of children with Down syndrome have undiagnosed anomalies of kidneys and urinary tract. These findings demonstrate that kidney development is remarkably affected in Down syndrome and strongly suggests that all affected individuals should be screened to assess for both kidney function and anatomical anomalies.

Supplementary Information The online version contains supplementary material available at https://doi.org/10.1007/s00467-022-05455-y.
Acknowledgements The authors thank Olof $\mathrm{H}$. Sundin, $\mathrm{PhD}$, for suggestions regarding selection criteria for the control group, as well as Mrs. Laurence Seidel for her assistance with some of the statistical analyses.

Funding This work was supported by The Belgian Kids' Fund for Pediatric Research of the Queen Fabiola Children's University Hospital and by the Department of Ophthalmology, Erasmus Hospital, Université Libre de Bruxelles, Brussels, Belgium. The funders had no role in the design and conduct of the study.

Data Availability All data are available upon request.

\section{Declarations}

Ethics approval Approval for this study was obtained from the Institutional Review Boards and Institutional Ethics Committees of both the Queen Fabiola Children's University Hospital (CEH 69/17) and the Erasmus Hospital (P2017/391; B4062017329655). All examinations were performed in accordance with the principles and tenets of the Declaration of Helsinki.

Consent to participate Written informed consent was obtained for all subjects with both parents providing consent.

\section{Consent for publication NA}

Conflict of interest The authors declare no competing interests.

\section{References}

1. Kallen B, Mastroiacovo P, Robert E (1996) Major congenital malformations in Down syndrome. Am J Med Gen 65:160-166

2. Cleves MA, Hobbs CA, Cleves PA, Tilford JM, Bird TM, Robbins JM (2007) Congenital defects among liveborn infants with Down syndrome. Birth Defects Res A Clin Mol Teratol 79:657-663

3. Kupferman JC, Druschel CM, Kupchik GS (2009) Increased prevalence of renal and urinary tract anomalies in children with Down syndrome. Pediatrics 124:e615-e621

4. Malaga S, Pardo R, Malaga I, Orejas G, Fernandez-Toral J (2005) Renal involvement in Down syndrome. Pediatr Nephrol 20:614-617

5. Kitamura A, Kondoh T, Noguchi M, Hatada T, Tohbu S, Mori KI, Matsuo M, Kunitsugu I, Kanetake H, Moriuchi H (2014) Assessment of lower urinary tract function in children with Down syndrome. Pediatr Int 56:902-908

6. Jain M, Singh A, Mantan M, Kapoor S (2014) Evaluation of structural anomalies of kidney and urinary tract in children with Down syndrome. Indian J Pediatr 81:734

7. Niamien-Attai C, Bacchetta J, Ranchin B, Sanlaville D, Cochat P (2017) Renal abnormalities in Down syndrome: a review. Arch Pediatr 24:1013-1018

8. Jaeger EA (1980) Ocular findings in Down's syndrome. Trans Am Ophthalmolo Soc 78:808-845

9. da Cunha RP, Moreira JB (1996) Ocular findings in Down's syndrome. Am J Ophthalmol 122:236-244

10. Postolache L (2019) Abnormalities of the optic nerve in Down syndrome and associations with visual acuity. Front Neurol 10:633

11. Woodhouse JM, Meades JS, Leat SJ, Saunders KJ (1993) Reduced accommodation in children with Down syndrome. Invest Ophthalmol Vis Sci 34:2382-2387 
12. Parsa CF, Almer Z (2008) Supranumerary optic disc vessels may indicate reduced systemic angiogenesis in Down syndrome. $\mathrm{Br} \mathbf{J}$ Ophthalmol 92:432-433

13. Postolache L, Parsa CF (2018) Brushfield spots and Wölfflin nodules unveiled in dark irides using near-infrared light. Sci Rep 8:18040

14. Parsa CF, Silva ED, Sundin OH, Goldberg MF, De Jong MR, Sunness JS, Zeimer R, Hunter DG (2001) Redefining papillorenal syndrome: an underdiagnosed cause of ocular and renal morbidity. Ophthalmology 108:738-749

15. Parsa CF (2008) Of Pax2 laboratory mice and human papillorenal investigations: maintaining the distinctions between cause and effect. J AAPOS 12:113-114

16. Parsa CF, Parsa A (2008) Diagnosing papillorenal syndrome: see the optic papilla. Pediatr Nephrol 23:1893-1894

17. Ariel I, Wells TR, Landing BH, Singer DB (1991) The urinary system in Down syndrome: a study of 124 autopsy cases. Pediatr Pathol 11:879-888

18. Naeye RL (1967) Prenatal organ and cellular growth with various chromosomal disorders. Biol Neonat 11:248-260

19. Mosteller RD (1987) Simplified calculation of body-surface area. N Engl J Med 317:1098

20. Schwartz GJ, Muñoz A, Schneider MF, Mak RH, Kaskel F, Warady BA, Furth SL (2009) New equations to estimate GFR in children with CKD. J Am Soc Nephrol 20:629-637

21. Jaffe M (1886) Über den Niederschlag, welchen Pikrinsäure in normalen Harn erzeugt und über eine neue Reaktion des Kreatinins. Z Physiol Chem 10

22. Varley H, Gowenlock AH, Bell M (1980) Practical clinical biochemistry, 5th edn. William Heinemann Medical Books, London

23. Ezeofor SN, Anyanwu GE, Obikili EN (2020) Reference indices for evaluating kidney dimensions in children using anthropometric measurements. SA J Radiol 24:1882

24. Stoll C, Dott B, Alembik Y, Roth MP (2015) Associated congenital anomalies among cases with Down syndrome. Eur J Med Genet 58:674-680

25. Ahmed S (1990) Vesico-ureteric reflux in Down's syndrome: poor prognosis. Aust N Z J Surg 60:113-116

26. Hicks JA, Carson C, Malone PS (2007) Is there an association between functional bladder outlet obstruction and Down's syndrome? J Pediatr Urol 3:369-374

27. Chicoine B, Sulo S (2015) Rate of urinary retention in adults with Down syndrome: a prospective study. J Am Board Fam Med 28:115-117

28. Pottel H, Hoste L, Delanaye P (2015) Abnormal glomerular filtration rate in children, adolescents and young adults starts below 75 $\mathrm{mL} / \mathrm{min} / 1.73 \mathrm{~m}(2)$. Pediatr Nephrol 30:821-828

29. Yamakawa S, Nagai T, Uemura O (2018) Down syndrome and mild kidney dysfunction. Pediatr Int 60:391-393

30. Coburn SP, Seidenberg M, Mertz ET (1967) Clearance of uric acid, urea, and creatinine in Down's syndrome. J Appl Physiol 23:579-580

31. Nishida Y, Akaoka I, Kobayashi M, Maruki K, Oshima Y (1979) Renal impairment in urate excretion in patients with Down's syndrome. J Rheumatol 6:103-107

32. Zorick TS, Mustacchi Z, Bando SY, Zatz M, Moreira-Filho CA, Olsen B, Passos-Bueno MR (2001) High serum endostatin levels in Down syndrome: implications for improved treatment and prevention of solid tumours. Eur J Hum Genet 9:811-814

33. Ryeom S, Folkman J (2009) Role of endogenous angiogenesis inhibitors in Down syndrome. J Craniofac Surg 20:595-596

34. Baek KH, Zaslavsky A, Lynch RC, Britt C, Okada Y, Siarey RJ, Lensch MW, Park IH, Yoon SS, Minami T, Korenberg JR, Folkman J, Daley GQ, Aird WC, Galdzicki Z, Ryeom S (2009) Down's syndrome suppression of tumour growth and the role of the calcineurin inhibitor DSCR1. Nature 459:1126-1130
35. Karihaloo A, Karumanchi SA, Cantley WL, Venkatesha S, Cantley LG, Kale S (2005) Vascular endothelial growth factor induces branching morphogenesis/tubulogenesis in renal epithelial cells in a neuropilin-dependent fashion. Mol Cell Biol 25:7441-7448

36. Marlier A, Schmidt-Ott KM, Gallagher AR, Barasch J, Karihaloo A (2009) Vegf as an epithelial cell morphogen modulates branching morphogenesis of embryonic kidney by directly acting on the ureteric bud. Mech Dev 126:91-98

37. Schwentner C, Oswald J, Lunacek A, Schlenck B, Berger AP, Deibl M, Fritsch H, Bartsch G, Radmayr C (2006) Structural changes of the intravesical ureter in children with vesicoureteral reflux-does ischemia have a role? J Urol 176:2212-2218

38. Murer L, Benetti E, Artifoni L (2007) Embryology and genetics of primary vesico-ureteric reflux and associated renal dysplasia. Pediatr Nephrol 22:788-797

39. Desogus M, Crobe A, Fraschini M, Ottonello G, Puddu M, Faa G, Fanos V (2016) Morphological changes in the kidney of fetuses with Down syndrome. J Pediatr Neonat Ind Med 5:e050125

40. Lo A, Brown HG, Fivush BA, Neu AM, Racusen LC (1998) Renal disease in Down syndrome: autopsy study with emphasis on glomerular lesions. Am J Kidney Dis 31:329-335

41. Smith DS (2001) Health care management of adults with Down syndrome. Am Fam Physician 64:1031-1038

42. American Academy of Pediatrics.Committee on Genetics (2001) Health supervision for children with Down syndrome. Pediatrics 107:442-449

43. Kute VB, Vanikar AV, Shah PR, Gumber MR, Patel HV, Engineer DP, Thakkar UG, Trivedi HL (2013) Down syndrome with endstage renal disease. Indian J Clin Biochem 28:429-432

44. Jafar TH, Schmid CH, Landa M, Giatras I, Toto R, Remuzzi G, Maschio G, Brenner BM, Kamper A, Zucchelli P, Becker G, Himmelmann A, Bannister K, Landais P, Shahinfar S, de Jong PE, de Zeeuw D, Lau J, Levey AS (2001) Angiotensin-converting enzyme inhibitors and progression of nondiabetic renal disease. A meta-analysis of patient-level data. Ann Intern Med 135:73-87

45. Wuhl E, Trivelli A, Picca S, Litwin M, Peco-Antic A, Zurowska A, Testa S, Jankauskiene A, Emre S, Caldas-Afonso A, Anarat A, Niaudet P, Mir S, Bakkaloglu A, Enke B, Montini G, Wingen AM, Sallay P, Jeck N, Berg U, Caliskan S, Wygoda S, HohbachHohenfellner K, Dusek J, Urasinski T, Arbeiter K, Neuhaus T, Gellermann J, Drozdz D, Fischbach M, Moller K, Wigger M, Peruzzi L, Mehls O, Schaefer F (2009) Strict blood-pressure control and progression of renal failure in children. N Engl J Med 361:1639-1650

46. Simeoni M, Armeni A, Summaria C, Cerantonio A, Fuiano G (2017) Current evidence on the use of anti-RAAS agents in congenital or acquired solitary kidney. Ren Fail 39:660-670

47. Schwartz GJ, Dana F (2009) Measurement and estimation of GFR in children and adolescents. Clin J Am Soc Nephrol 4:1832-1843

48. Du L, Zukotynski K, Hsiao E, Zurakowski D, Treves ST, Grant F (2009) Pediatric reference ranges for glomerular filtration rate determined by a single injection of Tc-99m DTPA. J Nucl Med 50:1375

49. Uemura $\mathrm{O}$, Nagai $\mathrm{T}$, Ishikura Ito $\mathrm{S}$, Hataya $\mathrm{H}$, Gotoh $\mathrm{Y}$, Fujita N, Akioka Y, Kaneko T, Honda M (2015) Reference glomerular filtration rate levels in Japanese children: using the creatinine and cystatin $\mathrm{C}$ based estimated glomerular filtration rate. Clin Exp Nephrol 19:683-687

50. Leion F, Hegbrant J, den Bakker E, Jonsson M, Abrahamson M, Nyman U, Björk J, Lindström V, Larsson A, Bökenkamp A, Grubb A (2017) Estimating glomerular filtration rate (GFR) in children. The average between a cystatin $\mathrm{C}$ - and a creatinine-based equation improves estimation of GFR in both children and adults and enables diagnosing Shrunken Pore Syndrome. Scand J Clin Lab Invest 77:338-344 
51. Regnault N, Kleinman KP, Rifas-Shiman SL, Langenberg C, Lipshultz SE, Gillman MW (2014) Components of height and blood pressure in childhood. Int J Epidemiol 43:149-159

52. Ramoshaba NE, Monyeki KD, Mpya J, Monyeki MS (2018) The relationship between sitting height, sitting height to height ratio with blood pressure among Polokwane private school children aged 6-13 years. BMC Public Health 17:973

53. Jaswal S, Jaswal IJ (1981) An anthropometric study of body size in Down syndrome. Indian J Pediatr 48:81-84

54. Costa L, Freire F, Bertapelli F, Campos LF, Santos LGTF, Gorla J (2013) Body proportions in children and adolescents with Down's syndrome. J Hum Growth Dev 23:198-202

55. Nishino T, Endo S, Miyano H, Umeda C, Tomii Y, Watanabe Y, Nakagawa M, Kakegawa D, Fujinaga S (2021) Is the estimated glomerular filtration rate formula useful for evaluating the renal function of Down syndrome? Pediatr Int 63:944-950

56. González-Agüero A, Ara I, Moreno LA, Vicente-Rodríguez G, Casajús JA (2011) Fat and lean masses in youths with Down syndrome: gender differences. Res Dev Disabil 32:1685-1693

57. Lee SC, Lim LM, Chang EE, Chiu YW, Hwang SJ, Chen HC (2019) Effect of differences in serum creatinine estimation methodologies on estimated glomerular filtration rate. Singapore Med J 60:468-473

Publisher's note Springer Nature remains neutral with regard to jurisdictional claims in published maps and institutional affiliations. 